\title{
Total Antioxidant Activity of Amaranth Leaves in Ontogenesis
}

\author{
Valery N. Zelenkov ${ }^{1^{*}}$, Anatoly A. Lapin ${ }^{2}$, Taisia G. Belonozhkina ${ }^{3}$, \\ Nadezhda L. Voropaeva ${ }^{3}$, Nikolay V. Shachnev ${ }^{3}$, Vladimir V. Karpachev ${ }^{3}$ \\ ${ }^{1}$ Federal State-financed Scientific Institute of Vegetable Production \\ ${ }^{2}$ Kazan State Energy University \\ ${ }^{3}$ Federal State-financed Scientific Institute "All-Russian Rapeseed Research Institute" \\ bionanotex_l@mail.ru
}

Keywords: antioxidant activity, amaranth leaves, total antioxidant activity (TAA) increase, the thermal activation of antioxidant activity

\begin{abstract}
The authors carried out in the fieldwork with a new variety of amaranth «Lipetsky». In order to identify qualitative and quantitative laws of manifestation of the total antioxidant activity of amaranth the leaves were collected in different phases of plant vegetation, dehydrated in mild conditions of air-shadow drying and subsequently dried under harsh conditions $105^{\circ} \mathrm{C}$ to a constant mass of samples. Testing of plant samples was carried out using a coulometric method of titration (author's method) of free bromine radicals generated in the aquatic environment by plant titrant (water extract dried in the shade at a temperature of $22^{\circ} \pm 3^{\circ} \mathrm{C}$ of leaves). It was examined the combined samples of 10 samples of plant leaves of different tiers and of different ages with field plot of 10 ha. Biometric averages of plants during the growing season: growth, the weight of plants, number of leaves, the weight of leaves, stem and inflorescence of the plant are given. This shows the dynamics of total antioxidant activity of leaves of amaranth during the growing season. The thermal stability of the total antioxidant activity (TAA) for combined extracts of 10 samples of leaves of different ages and from different parts of plants when they are drying at $105^{\circ} \mathrm{C}$ was tested. The dynamics of change, TAA aqueous extracts of the dried amaranth samples with different stages of the growing season corresponds to the previously identified trends in the availability of high quantitative values in the phase of mass budding beginning of flowering and minima in the initial growth phases (3-8 leaves) and ripening of seed for different varieties of amaranth. There were revealed the increase in antioxidant activity upon drying amaranth samples at $105{ }^{\circ} \mathrm{C}$, revealed a new type of qualitative dynamics of TAA, while vegetation with a characteristic quantitative changes by more than 50\% for the beginning of the growth phase (the first phase of 3-8 leaves) and the final phase of seed maturation.
\end{abstract}

\section{Introduction}

Amaranth is now increasingly used in manufacturing prophylactic treatment nutrition, medical cosmetics, hygiene products and means of human diseases prevention. Amaranth oil is characterized by its high content of squalene (up to $8 \%$ ) and unsaturated fatty acids - oleic, linoleic and lenolenic [1-3]. Unsaturated fatty acids affect the aggregation of blood platelets, cholesterol, and have an antisclerotic effect [3].

A promising direction in amaranth breeding is the production of new amaranth varieties with an increased antioxidant activity, not only in seeds, but also in green mass. The indication of the quantitative content of total antioxidants in amaranth seeds and grass is one of the significant targets in the amaranth breeding.

Conclusion, the work in the direction of studying the antioxidant properties of amaranth and research on the lability of this indicator during the ontogenesis of amaranth are relevant both for the characterization of specific varieties, and during breeding work to obtain bioactive raw materials for the food and pharmaceutical industry.

Earlier, in our works, it was shown that amaranth varieties obtained in the breeding process differ by more than 10 times in antioxidant activity of full-grown seeds. It became possible to 
identify several samples for variety testing and "Lipetsky" amaranth variety in the State Register of the Russian Federation.

The purpose of this work is to characterize the amaranth leaves of the new variety «Lipetsky» by the total indicator of antioxidant activity manifestations dried samples based on the total leaves of the plant in ontogenesis.

\section{Materials and Methods}

In this paper, quantitative indicators of the amaranth leaf TAA were under research [4]. The amaranth was cultivated on a 0.5 ha test field.

The selected amaranth leaves were dried in a lab site with natural air circulation in the shade at a room temperature. The leaves were chopped finely and sieved through a $0.8 \mathrm{~mm}$ sieve.

The table below shows the characteristics of amaranth leaf samples according to the methods of drying and final drying, their humidity content, sampling time, and a vegetation stage.

Table 1. Dried amaranth leaf sample characteristics according to the method of obtaining, sampling time and vegetation stage.

\begin{tabular}{|c|c|c|c|}
\hline \multirow{2}{*}{$\begin{array}{l}\text { Drying method } \backslash \\
\text { sample ID }\end{array}$} & \multirow{2}{*}{$\begin{array}{l}\text { Humidity } \\
\text { content, \% }\end{array}$} & \multicolumn{2}{|c|}{ Leaf sample selection } \\
\hline & & $\begin{array}{c}\text { Period from } \\
\text { seedtime, days }\end{array}$ & Vegetation stage \\
\hline At $105^{\circ} \mathrm{C} / 1_{0}$ & 0, a.d.s.* & 30 & leaf formation \\
\hline Air-shade / 1 & 4.63 & 30 & leaf formation \\
\hline At $105^{\circ} \mathrm{C} / 2_{0}$ & 0 & 40 & $\begin{array}{c}\text { stem intensive growth } \\
\text { vegetative mass increase }\end{array}$ \\
\hline Air-shade / 2 & 5.48 & 40 & $\begin{array}{l}\text { stem intensive growth } \\
\text { vegetative mass increase }\end{array}$ \\
\hline At $105^{\circ} \mathrm{C} / 3_{0}$ & 0 & 50 & inflorescence buttonhole \\
\hline Air-shade / 3 & 5.71 & 50 & inflorescence buttonhole \\
\hline At $105^{\circ} \mathrm{C} / 4_{0}$ & 0 & 60 & $\begin{array}{l}\text { mass budding and stem } \\
\text { growth completion }\end{array}$ \\
\hline Air-shade / 4 & 5.92 & 60 & $\begin{array}{l}\text { mass budding and stem } \\
\text { growth completion }\end{array}$ \\
\hline At $105^{\circ} \mathrm{C} / 5_{0}$ & 0 & 70 & mass flowering \\
\hline Air-shade / 5 & 6.22 & 70 & mass flowering \\
\hline При $105^{\circ} \mathrm{C} / 6_{0}$ & 0 & 80 & seed formation \\
\hline Air-shade / 6 & 6.30 & 80 & seed formation \\
\hline At $105^{\circ} \mathrm{C} / 77_{0}$ & 0 & 95 & seed formation completion \\
\hline Air-shade / 7 & 5.86 & 95 & seed formation completion \\
\hline At $105^{\circ} \mathrm{C} / 8_{0}$ & 0 & 105 & mature seeds \\
\hline Air-shade / 8 & 5.32 & 105 & mature seeds \\
\hline
\end{tabular}

*Note: a.d.s. - absolutely dry sample.

Coulometric analysis method using electrogenerated bromine radicals was applied to measure TAA of amaranth samples. The measuring device was coulometer "Expert-006-antioxidants" manufactured by NPK "Econiks Expert".

The crushed dried samples of amaranth brewed with boiling distilled water at a rate of $2 \mathrm{~g}$ of sample per $100 \mathrm{dm}^{3}$ of boiling water, the extraction was carried out with stirring on a magnetic stirrer for 15 minutes, the extracts were filtered before analysis. The samples of the were analyzed by the total antioxidant activity (TAA) of water extracts method using the coulometric titration method in the galvanostatic mode according to the certificated procedure MBI-01-00669068-13 in terms of the standard sample $(\mathrm{Ru})[6,7]$ through the modal value (mode) $[8,9]$ of 10 definitions. The relative error in determining the TAA (E rel.) was within $0.8-1.5 \%$ rel. The TAA was 
determined in $\mathrm{g}$ rutin $(\mathrm{Ru})$ in terms of $100 \mathrm{~g}$ of an absolutely dry sample (a.s.o.). Drying of the test samples was carried out using a moisture analyzer MX-50, A \& D Company (Japan) at $105{ }^{\circ} \mathrm{C}$ in parallel with the determination of moisture.

Data processing of test results was carried out in Microsoft Excel and Statistica 6.0 [10].

\section{Results}

Data on average plant height is presented in Fig. 1, overall plant weight - in Fig. 2.

Fig. 1 presents average height of amaranth plant during vegetation period. As it is seen, the plant reaches its maximum height on the 60th day of vegetation. By that time the average plant weight reaches $150 \mathrm{~g} /$ plant and indicates practically no change afterwards (Fig. 2). By the $60^{\text {th }}$ day the number of leaves reaches 22 with their average weight of $15 \mathrm{~g}$ (Figs. 3, 4).

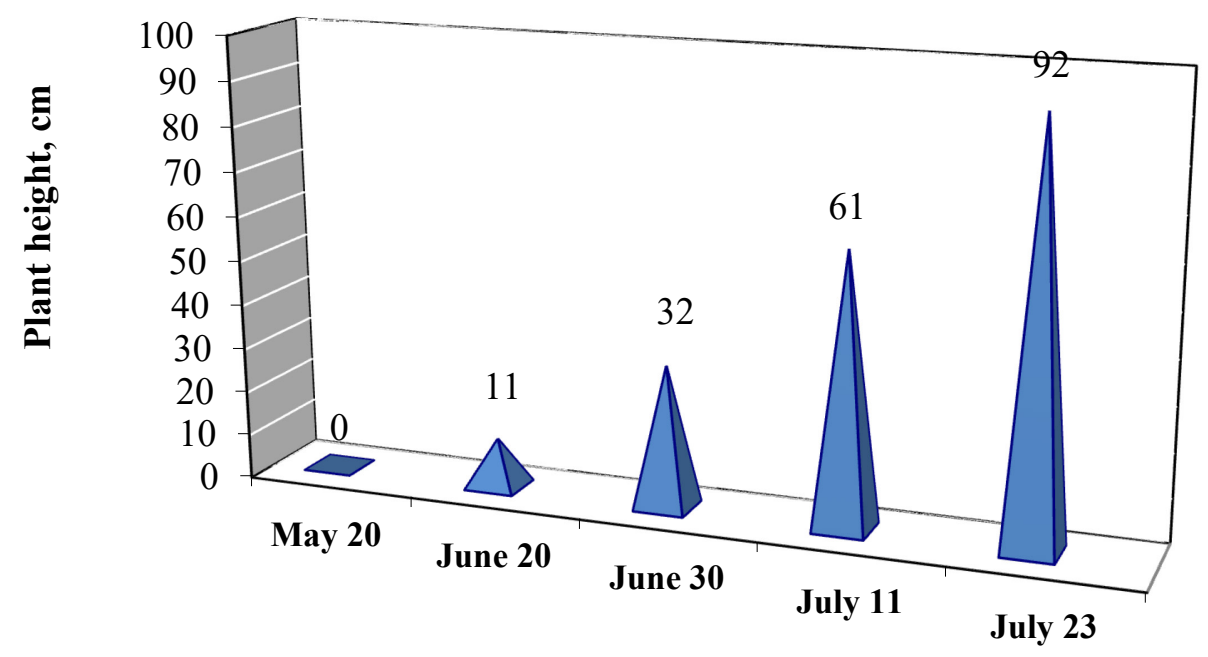

Sampling date

Figure 1. Dynamics of amaranth in the process of vegetation.

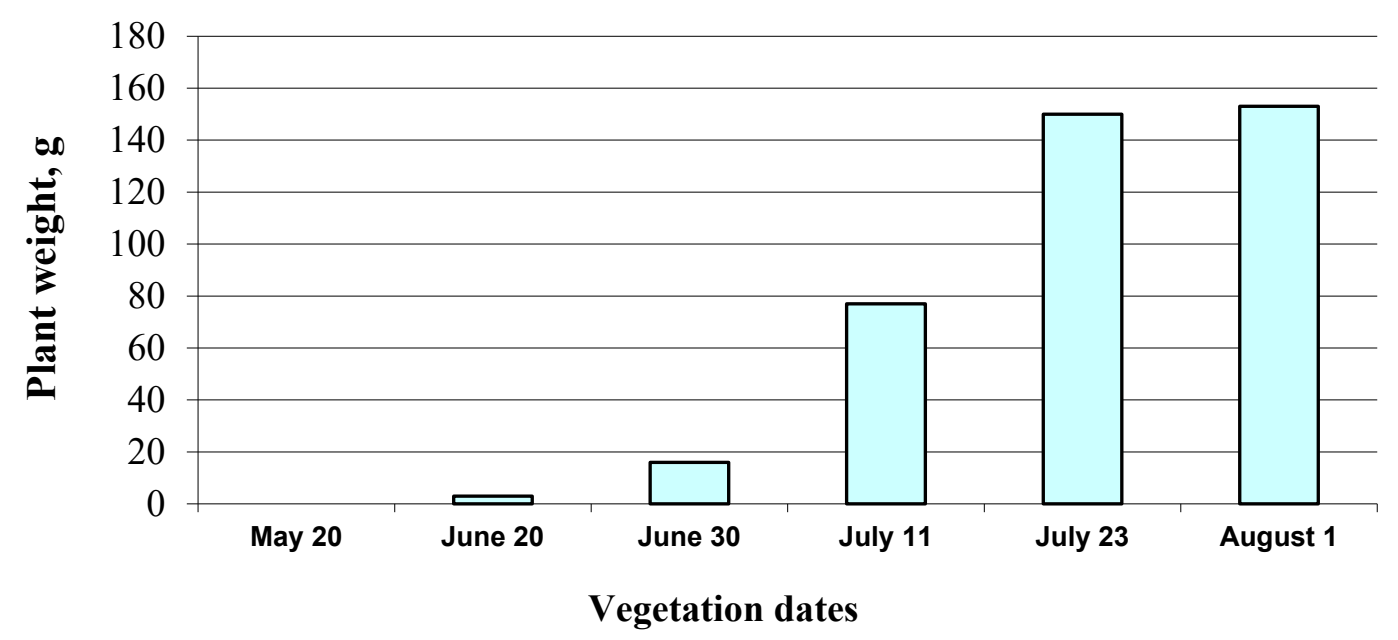

Figure 2. Change in amaranth plant mass during vegetation. 


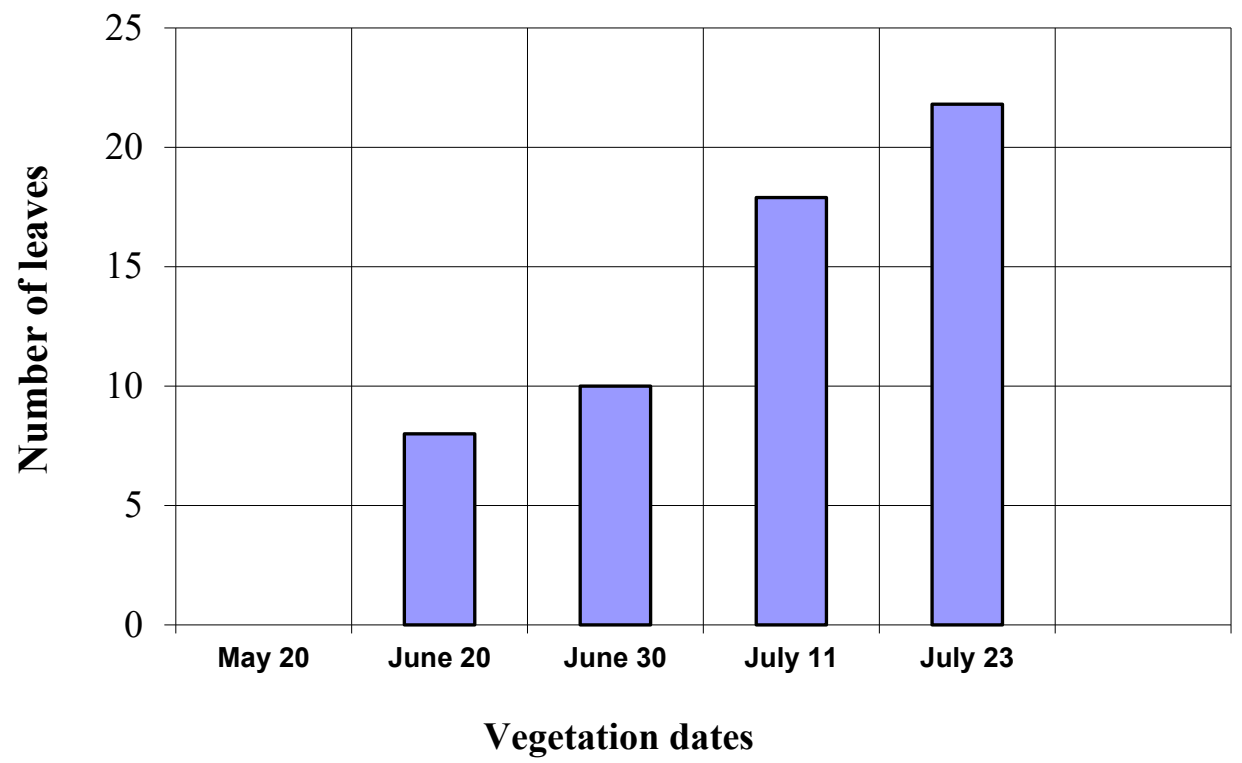

Figure 3. Dynamics of amaranth leaf formation during vegetation.

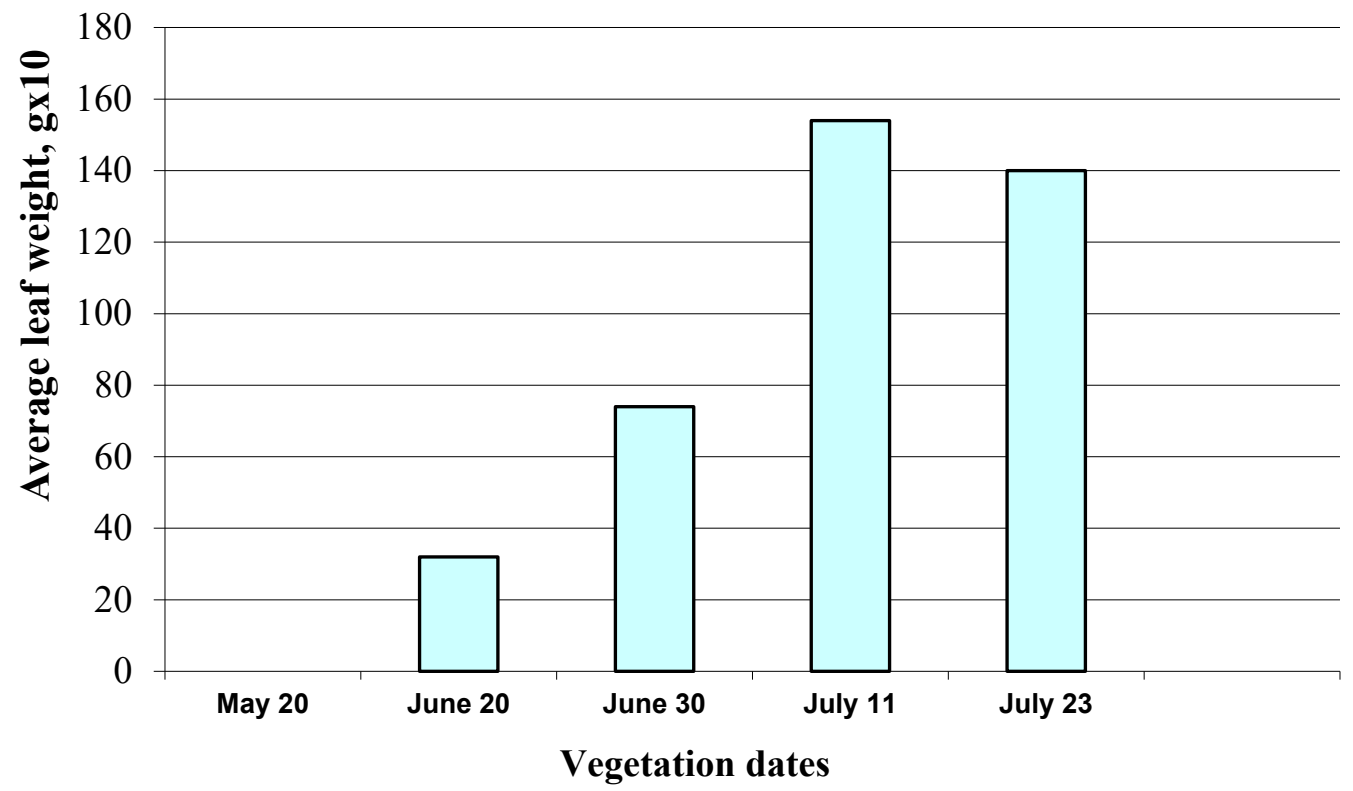

Figure 4. Dynamics of changes in the mass of one leaf of a plant during the growing of amaranth. 


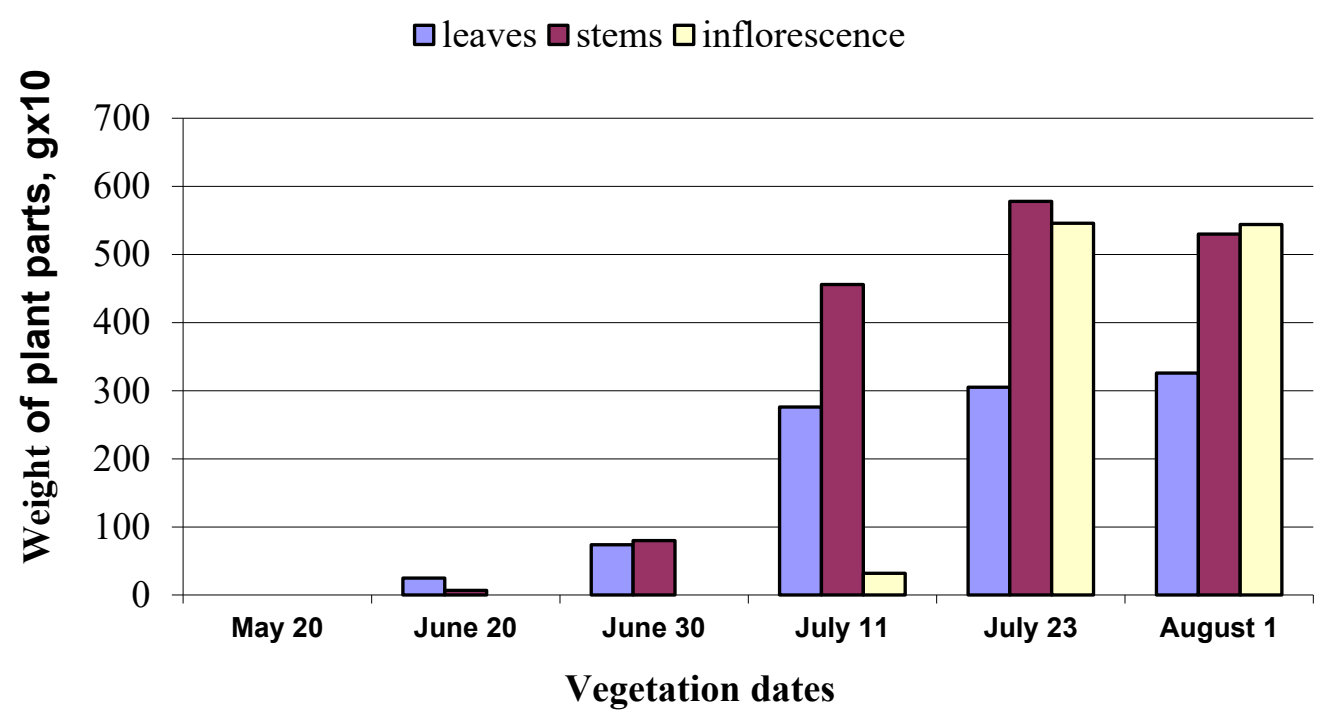

Figure 5. Change in the mass of plant parts during amaranth vegetation.

The ratio of leaf and stem weight by the end of second month is $1 \backslash 1$, inflorescence weight to stem or leaf weight is $1 \backslash 2$. On the 70th day this ratio remains unchanged, although there is a slight weight decrease of stems and leaves due to seed ripening. The weight of panicle is at least $20 \%$ to the total plant weight. The increase of this indicator is observed starting from the budding period (23 July), to mass flowering (1 August), up to fruiting period (August 1 - August 24). It creates favorable technological conditions for field harvesting.

As can be seen from Table 1, all leaf samples dried in air-shade conditions have substantially the same humidity content. The samples that were further exposed to final drying at $105{ }^{\circ} \mathrm{C}$ are almost absolutely dry samples.

Figs. 6 and 7 show graphs of TAA variations in samples obtained in both air-shade and final drying (at $105{ }^{\circ} \mathrm{C}$ ) conditions at different vegetation stages. Figs. 1 and 2 reveal fundamental difference between TAA levels at identical vegetation stages.

TAA changes in the samples exposed to air-shade drying conditions at a room temperature can be described as a chart with the following areas (Fig. 6):

1. Stable $(0.9 \% *$ TAA increase - 30-40 days $)$ - the initial phase of vegetation and the beginning of intensive growth

2. Decline (7.6\% TAA decrease - 40-50 days) - the beginning of rapid growth - the beginning of budding)

3. Incline (9.1\% TAA increase - 50-70 days) - the beginning of budding-mass flowering

4. Stable $(0.5 \% *$ TAA increase-decrease - 70-95 days) - mass flowering - wax seed maturity

5. Decline - (8.4\% TAA decrease - 95-105 days) wax seed maturity - mature seeds.

* - the values of the decrease-increase in TAA are not significantly different $(p=0.95)$.

As seen in Fig. 7, the dynamics of TAA changes in amaranth dried leaves during vegetation is divided into two specific sections that have their highest and lowest TAA indexes. The minimum TAA value for the standard dried samples comparing with A.D.S. is $3007 \mathrm{mg}$ and $3020 \mathrm{mg}$ of rutin per $100 \mathrm{~g}$ respectively; maximum - $3268 \mathrm{mg}$ and $3298 \mathrm{mg}$ of rutin per $100 \mathrm{~g}$ respectively for a 50day vegetation period (early budding); 105 days (the period of seed maturity); 40 days (beginning of stem intensive growth); 80 days (seed formation), respectively. The difference between the maximum and minimum TAA values for samples exposed to standard drying are $8.2 \%$ and $9.7 \%$ respectively for the two sections of 30-60 days and 60-105 days. This pattern of TAA value changes differs greatly from the described earlier in literature [6-9]. 


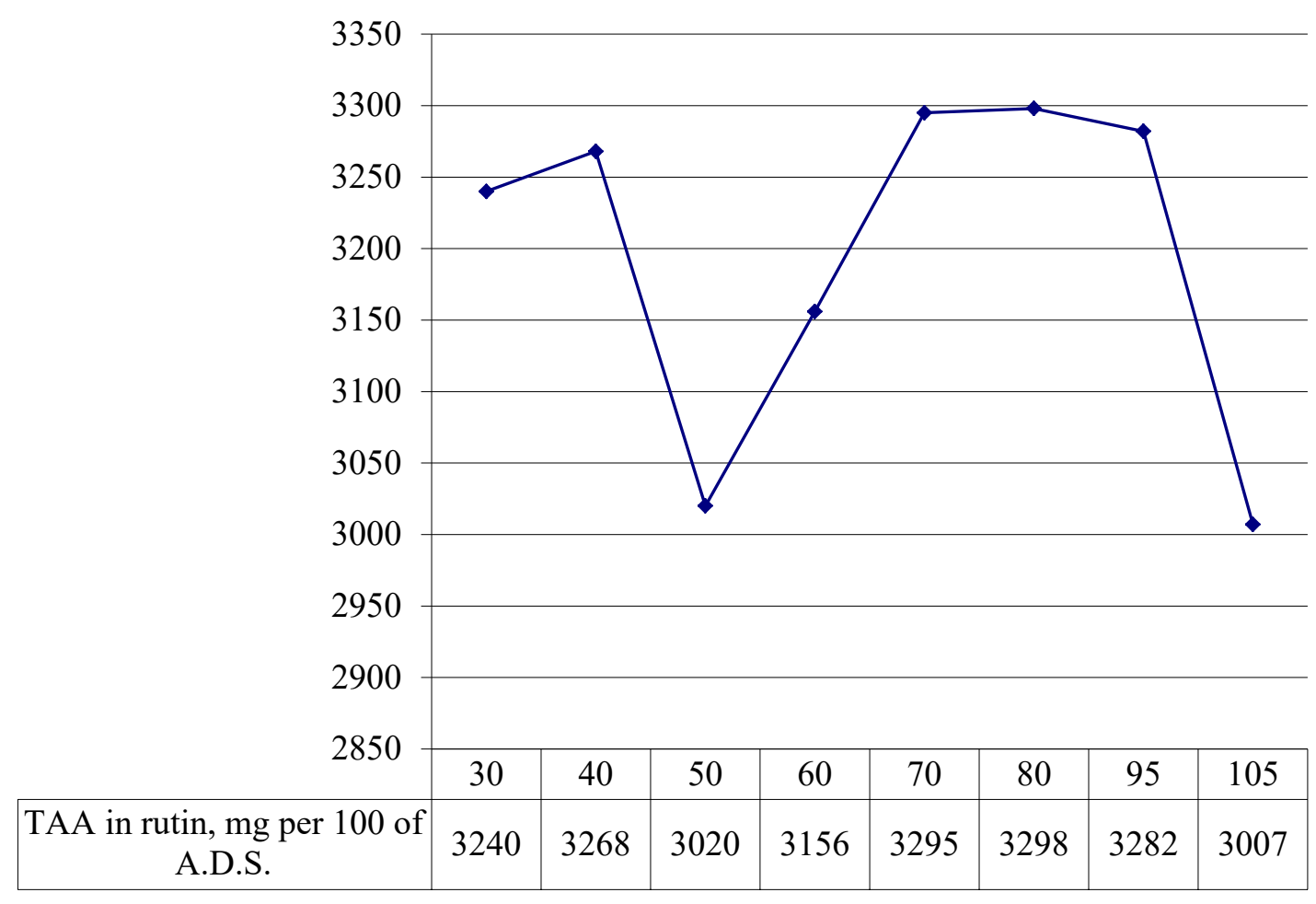

Vegetation dates, days

Figure 6. TAA (mg rutin per $100 \mathrm{~g}$ a.d.s.) of dried amaranth leave samples (air-shadow drying) at different periods of vegetation.

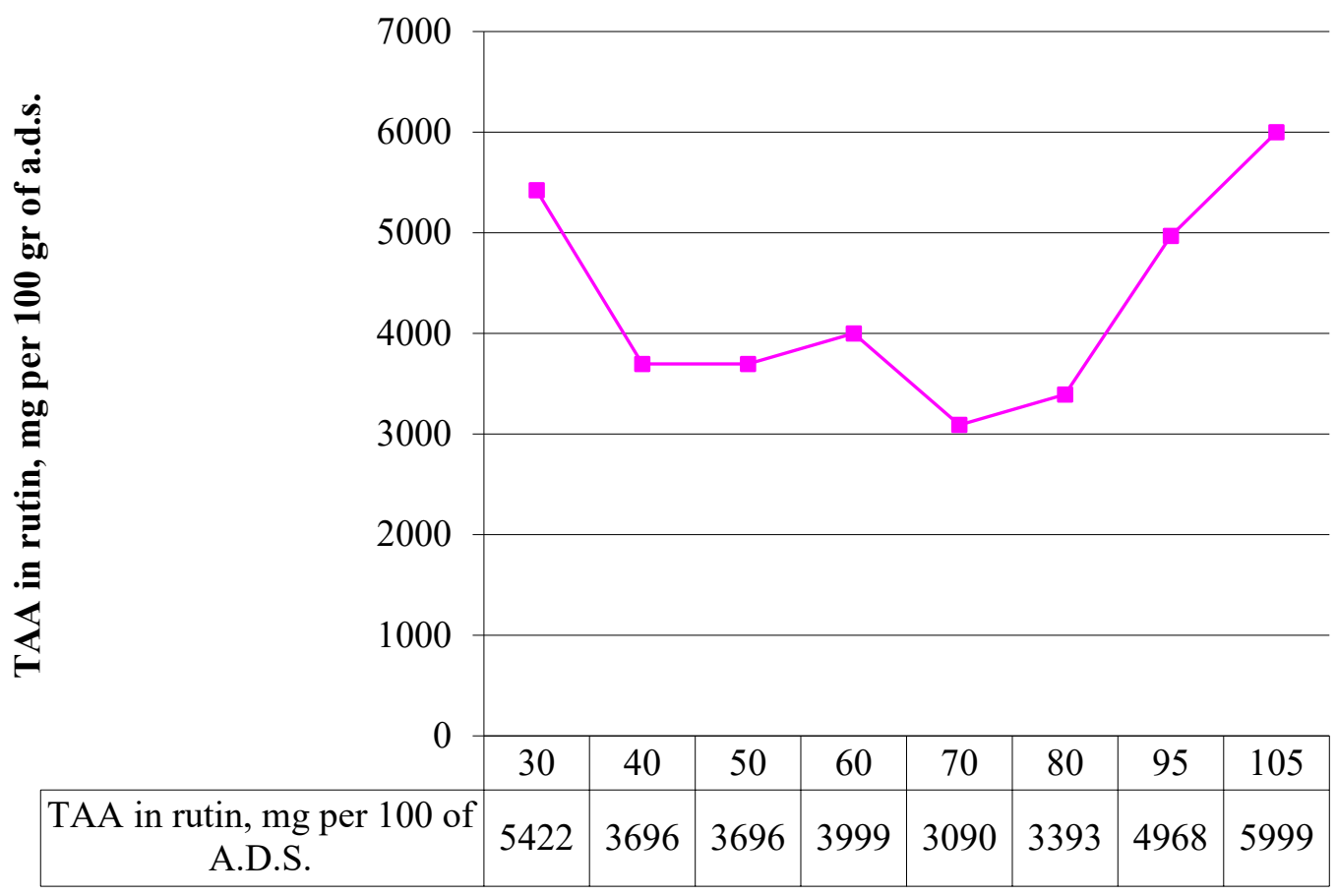

Vegetation dates, days

Figure 7. TAA (mg rutin per $100 \mathrm{~g}$ a.d.s.) of dried amaranth leave samples at different periods of vegetation after final drying at $105^{\circ} \mathrm{C}$. 


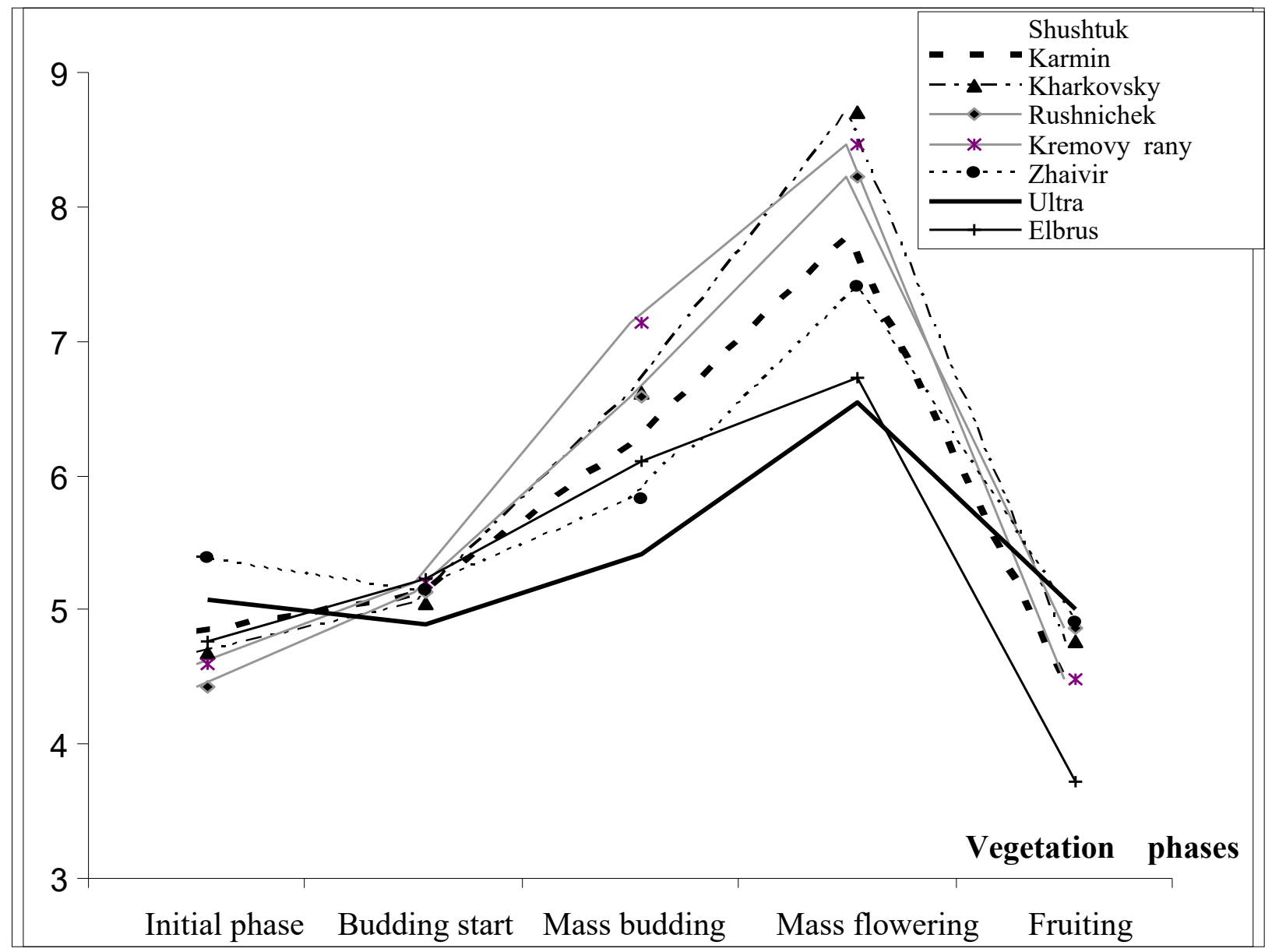

Figure 8. Leave-based water solutions in dynamics of amaranth growing (annual average) mg rutin per 100 g a.d.s. $(n=5, \rho=0.95)$ [6].

Fig. 8 represents TAA value changes in amaranth leaves during vegetation for different amaranth varieties [6].

Figs. 6 and 8 reveal similar pattern in TAA dynamics TAA during vegetation. Although, there are significant differences in TAA levels in the initial period of vegetation and flowering phase.

For all the previously studied amaranth varieties TAA value differences varied between the initial vegetation period and mass flowering stage from $30 \%$ (variety "Ultra") to $75 \%$ (variety "Kharkovsky") (Fig. 8). Thus, the dynamics of change, TAA, shown in Fig.1, which characterizes the new studied amaranth variety «Lipetsky».

Thus, earlier we managed to obtain a new variety of amaranth "Lipetsky» [4] with increased antioxidant activity of both plant seeds and amaranth leaves../Amaranth variety "Lipetsky" revealed an increased antioxidant activity of seeds (Fig. 6). It is 350\% higher than that of "Ultra" variety.

For samples for amaranth leaves (air-drying in the shadow at room temperature, a residual moisture content of 4.6 to $6.3 \%$ ) dried and cured plant samples to TAA at $105^{\circ} \mathrm{C}$, minimum value, TAA amounted to $3090 \mathrm{mg}$ rutin / $100 \mathrm{~g}$. TAA and a maximum of $5999 \mathrm{mg}$ rutin/ $100 \mathrm{~g}$. TAA for phases of the growing season of 70 days (flowering stage) and 40 days (early phase of the growing season). The difference between the maximum and minimum TAA values for samples dried at $105^{\circ} \mathrm{C}$ is $94 \%$ (Fig.7), which significantly distinguishes this type of samples of dried amaranth leaves from samples obtained by air-shadow drying.

$100 \mathrm{~g}$ of leaf may contain $6 \mathrm{~g}$ of water. Final drying deprives plant tissue of water, which increases antioxidant activity (Fig. 7).

Fig. 9 shows the dynamics of TAA changes in leaves exposed to both final and standard drying. Standard drying was performed at $25{ }^{\circ} \mathrm{C}$ resulting in humidity content of $4.6-5.3 \%$. ("Lipetsky" variety). It is seen that the decrease of TAA by $6.3 \%$ in finally dried samples (at $105^{\circ} \mathrm{C}$ ) was observed only on the 70th day of vegetation (mass budding stage). 
A characteristic feature of this option is the manifestation of TAA significant increase $(67.3 \%)$ at the initial phase of vegetation; $51.4 \%$ at wax maturity phase and $99.5 \%$ increase at full maturity phase. The fact of $100 \%$ AA increase due to amaranth leaf explosion to a high temperature has never been described in specialized literature.

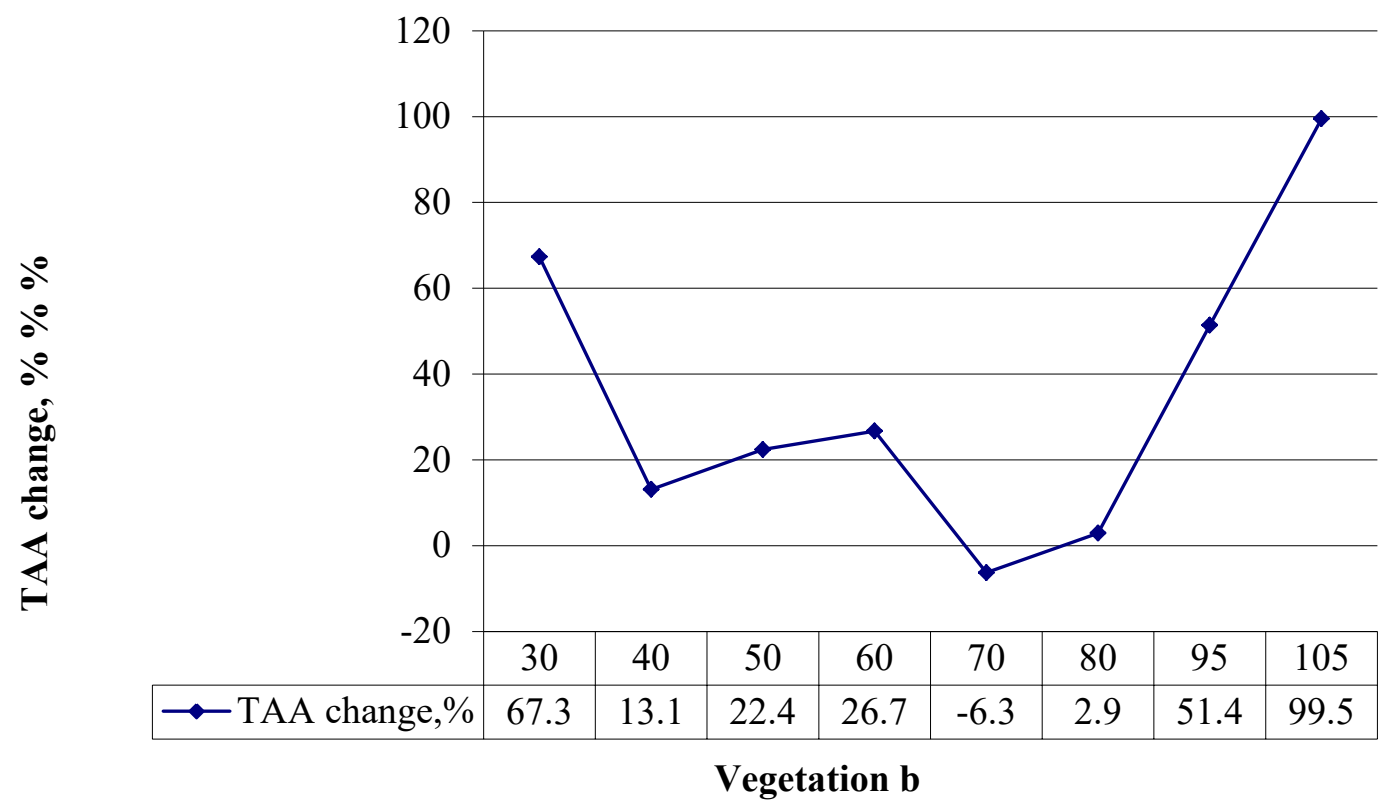

Figure 9. The dynamics of TAA changes in leaves exposed to both final and standard drying.

\section{Discussion and Analysis}

The fact of detection of essential activation of antioxidant activity up to $100 \%$ under temperature influence on dried leaf samples of the plant has not been previously described in the scientific literature.

According to state requirements, dried vegetables are allowed to have $14 \%$ of humidity content. The medical dried herbs are allowed to have $13 \%$ content, and should be dried under standard conditions (in air-ventilated facilities at a room temperature). A wide range of accelerating equipment and methods is used for vegetable drying. Though, drying temperature should not exceed $50{ }^{\circ} \mathrm{C}$ in order to preserve vitamins and protein. Final drying at $105{ }^{\circ} \mathrm{C}$ provides harsh water elimination together with chemical components of different nature (proteins, carbohydrates and fats).

Our research revealed TAA increase at initial and final vegetation stages in plant samples. This phenomena has not been described scientifically before and requires further explanation, modeling and experiment.

The observed effect of TAA increase in amaranth samples under the influence of high temperatures may be associated with the behavior of water in the plant. It also may be due unique physiological features of amaranth during vegetation under different environmental conditions, particularly, at extreme temperatures.

\section{Conclusions}

- There is a significant difference between the total antioxidant activity dynamics in the leaf samples at different vegetation phases dried at room temperature, and the ones exposed to final drying at $105{ }^{\circ} \mathrm{C}$.

- The fact of $100 \%$ total antioxidant activity increase due to amaranth leaf explosion to a high temperature has been revealed. The phenomena has not been described in specialized literature before. 
- The research revealed maximum total antioxidant activity increase at initial (beginning of leaf formation) and final (seed maturity) vegetation phases in plant samples after final drying.

\section{References}

[1] V.N. Zelenkov, V.A. Gulshina, A.A. Lapin, Amaranth. Biochemical and chemical portrait in ontogenesis, Moscow, Russian Academy of Natural Sciences, Russia, 2011. (in Russian)

[2] A.N. Karaseva at al., Amaranthus cruentus seed oil and functionally substituted esters based on them, in: Proceedings of the Conference "Chemistry and Technology of Natural Compounds", Syktyvkar, Russia, 2000, pp. 217-219. (in Russian)

[3] G.P. Fedoseeva, V.N. Zelenkov, Amaranth: introduction in the Middle Urals. Botanical, physiological and biochemical characteristics and fields of application, Moscow, Russian Academy of Natural Sciences, Russia, 2012. (in Russian)

[4] T.G. Belonozhkina et al., The patent for the selection achievement № 7501 amaranth (Amaranthus L.) "Lipetsky”. The priority dated 22.11.2012 by application № 8756509. Patent holder is Rapeseed Research Institute. (in Russian)

[5] GOST 1936-85. Tea. Acceptance rules and methods of analysis. Publishing House of the IPC standards, 2001. (in Russian)

[6] V.N. Zelenkov, A.A. Lapin, The total antioxidant activity. Methods of measurement by coulometric analyzer, MVI-01-00669068-13, All-Russian Research Institute of Vegetable Growing, Russian Academy of Agricultural Sciences, 2013. (in Russian)

[7] A.A. Lapin, N.G. Romanova, V.N. Zelenkov, Application of the galvanostatic coulometry method in the determination of antioxidant activity different types of biological raw materials and products of their processing, Russian State Agricultural Timiryazev Academy University, Russia, 2011. (in Russian)

[8] A.A. Lapin et al., Influence of infrared radiation on antioxidant activity of plant raw material and structured water adsorbed inside. Part 3. Features of structured water in alfalfa samples, Butlerov Communications. 47(9) (2016) 79-84.

[9] V.A. Gulshina et al., The main results of a comprehensive study of amaranth in the conditions of the TSChZ of the Tambov region, in: Unconventional Natural Resources, Innovative Technologies and Products. Collection of Scientific Papers, Vol 14, Russian Academy of Natural Sciences, Moscow, 2007, 126-136. (in Russian)

[10] K.N. Berk, P.M. Carey, Data analysis using Microsoft Excel, Williams Publishing House, 2005. 